\title{
Dissociation Constants of Some Alkanolamines at 293, 303, 318, and $333 \mathrm{~K}$
}

\author{
Rob J. Littel, " Martinus Bos, and Gerdine J. Knoop \\ Department of Chemical Technology, University of Twente, P.O. Box 217, 7500 AE Enschede, The Netherlands
}

The $\mathrm{pK}$, values were determined potentlometrically for the conjugate acids of 2-(2-aminoethoxy)ethanol (DGA),

2-(methylamino)ethanol (MMEA),

2-(tert-butylamino) ethanol (TBAE),

2-amino-2-methyl-1-propanol (AMP),

$\boldsymbol{N}$-methyldlethanolamine (MDEA),

2-(dimethylamino)ethanol (DMMEA),

2-(diethylamino)ethanol (DEMEA), and

2-(dilsopropylamino)ethanol (DIPMEA) at 293, 303, 318, and $333 \mathrm{~K}$.

\section{Introduction}

Alkanolamine solutions are used frequently to remove acidic components (e.g., $\mathrm{H}_{2} \mathrm{~S}, \mathrm{COS}$, and $\mathrm{CO}_{2}$ ) from natural and refinery gases. Industrially important alkanolamines for this operation are the secondary amines diethanolamine (DEA) and disopropanolamine (DIPA) and the tertiary amine $N$-methyldiethanolamine (MDEA). Usually aqueous solutions of these alkanolamines are applied; however, combined solvents like water and sulfolane in the Shell Sulfinol process are also used (1). Often there is no reason to remove $\mathrm{CO}_{2}$; therefore, selective absorption of sulfur compounds from acid gas streams may lower the costs of the treating process considerably (2).

Selective absorption of particularly $\mathrm{H}_{2} \mathrm{~S}$ is among other achieved by reducing the reaction rate of $\mathrm{CO}_{2}$. Generally this reaction rate is for tertiary amines lower than for primary and secondary amines, which explains the increasing popularity of MDEA-based processes for selective absorption. Also processes based on sterically hindered (secondary) amines, like the Exxon Flexsorb process, seem to be suitable for this purpose. In order to be able to improve the selectivity, extensive knowledge of the reaction of $\mathrm{CO}_{2}$ with alkanolamines is needed. In the past decade, a large number of articles have been published on this subject (e.g., Versteeg and Van Swaaij $(3,4)$ ). Apart from the reaction rate of $\mathrm{CO}_{2}$ with alkanolamines, also the capacity of alkanolamines for acidic components is an important factor in gas treating processes.

For both $\mathrm{CO}_{2}$ reaction rate and capacity, the dissociation constant of the alkanolamine applied is an important variable. Versteeg and Van Swaaij (3) reported for primary and secondary amines a Bronsted relationship between the secondorder rate constant for the formation of the $z$ witterion and the dissociation constant of the alkanolamine. Also for tertiary amines, a similiar relationship at $293 \mathrm{~K}$ between the secondorder rate constant and the dissociation constant of the alkanolamine was observed (4).

Dissociation constants of various alkanolamines at various temperatures have been accumulated by Perrin (5). Schwabe et al. (6) published data for $N$-methyldiethanolamine at 298 , 308,318 , and $333 \mathrm{~K}$. For diethanolamine and dilisopropanolamine in an aqueous $1.00 \mathrm{M}$ potassium chloride solution at temperatures of $293,303,313$, and $323 \mathrm{~K}$, information was reported by Blauwhoff and Bos (7). Antelo et al., (8) studied the influence of the ionic composition of the medium on the dissociation constants of monoethanolamine, diethanolamine, and triethanolamine at $298 \mathrm{~K}$. They found a linear relationship between $\mathrm{pK}$ and $I^{1 / 2}$
Table I. pH Values of the Calibration Buffers

\begin{tabular}{ccccc}
\hline temperature, & \multicolumn{4}{c}{$\mathrm{pH}$} \\
\cline { 2 - 5 } $\mathrm{K}$ & buffer 1 & buffer 2 & buffer 3 & buffer 4 \\
\hline 293 & 2.00 & 4.00 & 7.00 & 10.00 \\
303 & 2.00 & 4.01 & 6.98 & 9.89 \\
318 & 2.00 & 4.67 & 6.84 & 9.04 \\
333 & 2.00 & 4.69 & 6.84 & 8.96
\end{tabular}

Although the dissociation constants of well-known and industrially important alkanolamines have been reported at several temperatures, dissociation constants of less common alkanolamines are still lacking. Therefore, the aim of the present investigation was to provide additional and reliable dissociation constants for various alkanolamines at several temperatures.

\section{Experimental Section}

2.1. Chemicals. For the experiments, the chemicals used were obtained from Janssen Chimica [2-(methylamino)ethanol (MMEA), 2-(tert-butylamino)ethanol (TBAE), 2-amino-2-methyl1-propanol (AMP), $\mathrm{N}$-methyldiethanolamine (MDEA), and 2-(diisopropylamino)ethanol (DIPMEA)] and Merck [2-(dimethylamino)ethanol (DMMEA) and 2-(diethylamino)ethanol (DEMEA)]. All these compounds were p.a. quality. Texaco Chemical Co. provided 2-(2-aminoethoxy)ethanol (DGA). All compounds were used as received.

Aqueous hydrochloric acid $(0.1000 \mathrm{M})$ was used as titrant and prepared from Merck Titrisol ampules solved in aqueous $0.1 \mathrm{M}$ tetraethylammonium chloride (TEACl, Merck p.a.; recrystallized twice from chloroform/ethyl acetate, washed with diethyl ether, and dried under vacuum conditions at $120^{\circ} \mathrm{C}$ ).

The following $\mathrm{pH}$ buffers were used in the calibration of the glass electrode: $\mathrm{pH}=2.00,4.00,7.00,9.00,10.00,4.66$, 6.88 , and 9.22 (all from Merck; $\mathrm{pH}$ values given at $293 \mathrm{~K}$ ).

All solutions were prepared with carbon dioxide free double-distilled water.

2.2. Procedure. The $p K_{\mathrm{a}}$ values of the conjugate acids were determined by potentiometric titration of the basic compounds $\left(0.30-0.35 \times 10^{-3} \mathrm{~mol}\right.$ in $25 \times 10^{-3} \mathrm{~L}$ of solution) at constant ionic strength $(0.1 \mathrm{M} \mathrm{TEACl}$ ) with $0.1000 \mathrm{M} \mathrm{HCl}$ (in 0.1 $M$ TEACI). The titration curves were recorded by computerized equipment consisting of a Mettler Model DV11 motorburet, a Knick industrial pH meter, type DIN, and a thermostated titration vessel. The $\mathrm{pH}$ meter was read by a digital voltmeter (Tekelec Airtronic, 4 digits), which was connected to the computer (PDP-11/84, Digital Equipment Corp.) via a DR11 digital I/O interface. The motorburet was driven by the computer also via this interface. Calibration of the combined glass/reference electrode (Metrohm Model AG9100) was done by linear regression of the millivolt response of the electrode on four butfer solutions. The $\mathrm{pH}$ values used are presented in Table I.

The sample and buffer solutions were thermostated at the required temperature $( \pm 0.1 \mathrm{~K})$ before use. Carbon dioxide was excluded from the titrations by flushing the titration vessel with nitrogen.

2.3. Calculation. The $p K_{\mathrm{a}}$ values of the samples were calculated from titration data (per titration curve, 60 or more $\mathrm{pH}-10^{-3} \mathrm{~L}$ data pairs) with the use of the SUPERQUAD computer program (Gans et al. (9)). As this program does not take into account the values of the activity coefficients in its equations, 
Table II. $\mathrm{p} K$, Values of Conjugate Acids of Alkanolamines ${ }^{a}$

\begin{tabular}{lrlll}
\hline \multicolumn{1}{c}{ compound } & $293 \mathrm{~K}$ & $303 \mathrm{~K}$ & $318 \mathrm{~K}$ & $333 \mathrm{~K}$ \\
\hline N-methyldiethanolamine & 8.76 & 8.49 & 8.28 & 7.99 \\
2-(dimethylamino)ethanol & 9.23 & 8.99 & 8.69 & $8.36^{b}$ \\
2-(2-aminoethoxy)ethanol & 9.62 & 9.31 & 8.98 & 8.60 \\
2-(diethylamino)ethanol & 9.76 & $9.47^{b}$ & $9.16^{b}$ & $8.71^{\mathfrak{c}}$ \\
2-amino-2-methyl-1-propanol & 9.88 & 9.52 & 9.20 & 8.78 \\
2-(methylamino)ethanol & 9.95 & 9.64 & 9.35 & 8.94 \\
2-(diisopropylamino)ethanol & 10.14 & 9.82 & 9.53 & 9.13 \\
2-(tert-butylamino)ethanol & 10.29 & 9.94 & 9.64 & 9.28
\end{tabular}

${ }^{a}$ Accuracy, $\pm 0.02 \mathrm{pK}$ unit. $K_{\mathrm{a}}$ values in $\mathrm{mol} / \mathrm{L}$. ${ }^{b}$ Accuracy, $\pm 0.03 \mathrm{pK}$ anit. 'Accuracy, $\pm 0.04 \mathrm{pK}_{\mathrm{a}}$ unit.

the following steps were used to obtain the thermodynamically correct $p K_{a}$ values for infinite dilution: (1) conversion of the thermodynamic $K_{w}$ value to the "formal" value to be used as input by the SUPERQUAD program and (2) conversion of the $\mathrm{p} K_{\mathrm{a}}$ value given by the computer program to its thermodynamic value. The activity coefficients needed for steps 1 and 2 were calculated by the Debye-Hückel equation:

$$
-\log \left(\gamma_{i}\right)=\frac{A z_{i}^{2} I^{1 / 2}}{1+B k_{i} I^{1 / 2}}
$$

The values of $A$ and $B$ in this equation at the various temperatures were taken from Manov et al. (10). The ionic radius parameters $k$ used in these calculations were obtained from Kielland (11): $k=9(\mathrm{H}), k=3(\mathrm{OH}), k=4$ (MMEA, AMP, DMMEA, DGA), $k=5$ (TBAE, DIPMEA, MDEA, DEMEA). The $p K_{w}$ values used were taken from literature $(12)$. The Debye-Hückel equation (1) represents activity coefficients with very good accuracy up to $K=0.1 \mathrm{M}(13,14)$.

\section{Results and Discussion}

In the procedure outlined in the preceding text, it should be noted that the response of the glass electrode must be calibrated in terms of the concentration (not the activity) of the hydrogen ion. For titrations in a medium of constant electronic strength, this difference tends to be canceled by the difference of the liquid junction potentials between standard buffers and the titration medium (15). For the correctness of the complete procedure to be ascertained, the $\mathrm{pK} \mathrm{K}_{\mathrm{a}}$ values of benzoic acid and imidazole were determined at $298 \mathrm{~K}$. The value for benzoic acid was found to be $4.22 \pm 0.02$ and equals the literature value of $4.20(16)$ within experimental error. For imidazole a value of $7.08 \pm 0.02$ was found. The literature values for imidazole $(17-20)$ were extrapolated to zero ionic strength with the help of eq 1 and coincide with the present result within experimental error. Furthermore, the inertness of the ionic strength buffer toward the alkanolamines was checked by carrying out some titrations at various buffer concentrations.

All determinations were carried out in triplicate, and the results were reproducible within $\pm 0.02 \mathrm{pK}$ unit. The data given in Table II are the mean values of these triplicate measurements. The SUPERQUAD program calculates the accuracy of its results based on the fit of the experimental data to the theoretical equations and the experimental error in the volume of titrant added $\left( \pm 0.02 \times 10^{-3} \mathrm{~L}\right)$. In almost all cases, this error was $\pm 0.02 \mathrm{pK}$ anit.
For $N$-methyldiethanolamine, some $\mathrm{pK}$ a values were determined by Schwabe et al. (6). Their values deviate systematically from our values, the difference being $-0.12 \mathrm{pK}$ anits. This discrepancy cannot be explained from the approximations they make (i.e., equal activity coefficients for the $\mathrm{H}^{+}$and the $\mathrm{Cl}^{-}$ion and the use of the limiting law of Debye-Hückel up to concentrations of $0.04 \mathrm{M}$ ), which account only for a $0.01-0.04$ $\mathrm{pK}$ a units difference over the concentration range studied. It may be possible that the discrepancy between the present results and those of Schwabe et al. originates from the use of two different calibration methods for the $\mathrm{pH}$ scale. Schwabe et al. use the standard potential of the calomel electrode as given by Hills and Ives (21) (i.e., $0.26796 \mathrm{~B}$ ) to fix their $\mathrm{pH}$ scale. In this work the $\mathrm{pH}$ scale was established with the use of the newer NBS standard buffer solutions (22).

\section{Glossary}

$A, B \quad$ constants, see eq 1

$I \quad$ ionic strength

$k \quad$ ionic radius parameter, see eq 1

$M \quad$ molarity [mol/L]

$K_{\mathrm{a}} \quad$ acid dissociation constant at $I=0[\mathrm{~mol} / \mathrm{L}]$

$z \quad$ charge number

$\gamma \quad$ activity coefficient

Registry No. DGA, 929-06-6; MMEA, 109-83-1; TBAE, 4620-70-6; AMP, 124-68-5; MDEA, 105-59-9; DMMEA, 108-01-0; DEMEA, 100-37-8; DIPMEA, 96-80-0.

\section{Literature Clted}

(1) Kohl, A. L.; Rlesenfeld, F. C. Gas Puriflcation; Gulf Publishing Co.: Houston, TX, 1979.

(2) Blauwholf, P. M. M.; Kamphuis, B.; van Swaaij, W. P. M.; Westerterp, K. R. Chem. Eng. Proc, 1985, 19, 1.

(3) Versteeg, G. F.; van Swaai], W. P. M. Chem. Eng. Sci. 1988, 43, 573.

(4) Versteeg, G. F.; van Swaaij, W. P. M. Chem. Eng. Sci. 1988, 43, 587.

(5) Perrin, D. D. Dissociation Constants of Organic Bases in Aqueous Solution; Butterworth: London, 1965.

(6) Schwabe, K.; Graichen, W.; Splethoff, D. Z. Phys. Chem. (Munich) $1959,20,68$.

(7) Blauwhoff, P. M.; Bos, M. J. Chem. Eng. Data 1981, 26, 7

(8) Antelo, J. M.; Arce, F.; Casado, J.; Sastre, M.; Varela, A. J. Chem. Eng. Data 1984, 29, 10.

(9) Gans, P.; Sabatini, A.; Vacca, A. J. Chem. Soc., Dalton Trans. 1983, 1195.

(10) Manov, G. G.; Bates, R. G.; Hamer, W. J.; Acree, S. F. J. Am. Chem. Soc. 1943, 65, 1765 .

(11) Kielland, J. J. Chem. Am. Soc. 1937, 59, 1675.

(12) Landolt-Bornstein. Zahlenwerte und Funktionen; Springer-Verlag: Berlin, 1960; Vol. II, Band 7, p 841.

(13) Kortüm, G. Textbook of Electrochemistry; Elsevier: Amsterdam, 1951 ; Vol. I.

(14) Robinson, R. A.; Stokes, R. M. Electrolyte Solutions; Butterworth: London, 1959.

(15) Irving, H. M.; Miles, M. G.; Pettit, L. D. Anal. Chim. Acta 1967, 38, 475.

(16) Landolt-Bornstein. Zahlenwerte und Funktionen; Springer-Verlag: Berlin, 1960; Vol. II, Band 7, p 867.

(17) Tanford, C.; Wagner, M. L. J. Am. Chem. Soc. 1953, 75, 434.

(18) Edsall, J. T.; Felsenfeld, G.; Goodman, D. S.; Gurd, F. R. N. J. Am. Chem. Soc. 1954, 76, 3054.

(19) Mickel, B. L.; Andrews, A. C. J. Am. Chem. Soc. 1955, 77, 5291.

(20) Brooks, P.; Davidson, N. J. Am. Chem. Soc. 1960, 82, 2118.

(21) Hills, G. J.; Ives, D. J. G. J. Chem. Soc. $1951,318$.

(22) Bates, R. G.; Guggenheim, E. A. Pure Appl. Chem. 1960, 1, 163.

Recelved for review April 18, 1989. Revised December 26, 1989. Accepted February 6, 1990. 